\title{
ULTRASOUND-ASSISTED EXTRACTION IN DELIGNIFICATION PROCESS TO OBTAIN HIGH PURITY CELLULOSE
}

\author{
JIA JUN POON, MEI CHING TAN and PECK LOO KIEW \\ Department of Chemical and Petroleum Engineering, Faculty of Engineering, \\ Technology and Built Environment, UCSI University, 56000 Cheras, Kuala Lumpur, Malaysia \\ Corresponding author: M. C. Tan,tanmc@ucsiuniversity.edu.my
}

Received April 4, 2020

\begin{abstract}
The effect of ultrasound-assisted extraction (UAE) on the delignification of kapok fiber to obtain high purity cellulose was studied. Lignin from lignocellulosic material is usually removed by the sodium chlorite solvent extraction method. Although this method can obtain high purity cellulose, it requires $9 \mathrm{~h}$ of treatment. Ultrasound sonication was introduced to reduce the treatment time and improve cellulose purity. Kapok fiber treated with UAE at 70\% sonication power, with the frequency of $53 \mathrm{kHz}$, for $20 \mathrm{~min}$ at $40{ }^{\circ} \mathrm{C}$, allowed obtaining cellulose with similar purity to that achieved by the conventional method, after it underwent the UAE delignification process for three times. Fourier transform infrared (FTIR) spectroscopy and thermogravimetric analysis (TGA) were performed to analyse the characteristics and purity of treated kapok cellulose, respectively. The results showed that delignification by UAE, using lower operating temperatures and shorter treatment time, was much more effective compared to the conventional method.
\end{abstract}

Keywords: kapok fiber, delignification, ultrasound, extraction, cellulose

\section{INTRODUCTION}

Cellulose is an organic compound commonly found in the cell walls of plants and is known as one of the most abundant organic macromolecules on the Earth. Plant-based cellulose is found in a mixture with lignin, hemicelluloses and other substances. ${ }^{1}$ Purification procedures are required to extract pure cellulose from lignocellulosic biomass.

In recent years, plant-based cellulose has been commonly used in the production of biodegradable plastics due to its high biodegradability, high mechanical strength and environmental friendliness. ${ }^{2}$ In addition to the synthesis of bioplastics, cellulose is also widely used in many industries, such as wood and paper, cosmetics, clothes and pharmaceutical industries. ${ }^{3}$ Cellulose derivatives, such as cellulose ether, cellulose ester and cellulose acetate, are commonly produced to suit different uses and applications. $^{4}$

In recent years, many researchers have shown interest in kapok fiber and a series of research studies have been conducted to understand and explore its properties and possible usage. From previous studies, kapok fiber is often subjected to pretreatments to enhance its intrinsic properties and modify its surface characteristics, which include chemical treatment, solvent treatment, acetyl treatment and physical treatment, to make it suitable for use in enrichment culture of lignocellulose-degrading bacteria, ${ }^{5}$ as an oil absorbent ${ }^{6}$ or as a colour dye and heavy metal ion absorbent. $^{7}$

Kapok is a type of silky fiber that encloses the seeds of kapok trees (Ceiba pentandara). The kapok fiber is in yellowish or light brown colour and extremely light, soft, resilient, moistureresistant, buoyant and brittle. ${ }^{8}$ Kapok fiber consists of hollow air-filled lumen and has high void content, which makes it a suitable material to be used as insulation medium against sound and heat. It is commonly used as stuffing for bedding, pillows, life jackets and sleeping bags. ${ }^{9}$ Like most lignocellulosic fibers, kapok fiber mainly consists of cellulose, lignin and hemicelluloses. ${ }^{10}$ According to Draman et al. ${ }^{11}$ kapok fiber contains $53.40 \%$ of cellulose, $20.73 \%$ of lignin and $29.63 \%$ of hemicelluloses. Since the plantation of kapok fiber is easy and cheap to obtain, and it is highly rich in cellulose, kapok 
fiber has become an alternative source of natural cellulose for further application. Cellulose fiber usually has better elasticity and flexibility than mineral fiber, which allows it to maintain a high aspect ratio in the manufacturing process. ${ }^{12}$

Although kapok fiber has become one of the most popular research topics over the years, the information on cellulose extraction from kapok fiber is very limited. Cellulose is commonly obtained by the conventional extraction method. Conventionally, high purity cellulose from kapok fiber is obtained by extracting it with solvent treatment and alkaline treatment. Solvent treatment is mainly used to remove lignin from the fiber and alkaline treatment is to remove hemicelluloses. ${ }^{11}$ The conventional method of extraction is sufficient enough to produce high purity cellulose. However, it requires a long treatment duration and high operating temperature to achieve high purity cellulose. In previous studies, several approaches have been introduced to enhance the extraction of cellulose. Acidic ionic liquid was used as a solvent in the delignification of lignocellulosic biomass and sugarcane bagasse. ${ }^{13,14}$ Ultrasonication treatment has been introduced to enhance cellulose extraction from oil palm empty fruit bunch fibers. ${ }^{15}$ Among all the chemical treatments involved in the extraction of cellulose, solvent treatment (delignification) required the longest treatment time. $^{11}$

In this study, the ultrasound-assisted extraction (UAE) method is introduced in the delignification process to achieve high purity cellulose with shorter reaction time and lower operating temperature. UAE is a process that uses acoustic energy and solvent to extract target compounds from various plants. The use of ultrasound in the extraction process will technically propagate the ultrasound pressure waves and produce cavitation phenomena. ${ }^{16}$ The collapse of cavitation bubbles caused by the UAE will result in the breakage of cell walls and release the contents of the cells into the extraction medium. ${ }^{17}$ This alternative extraction technique is user-friendly and efficient. Ultrasound-assisted extraction can provide faster kinetics during the reaction and improve the extraction yield. The operating temperature can also be reduced with the assistance of ultrasound. ${ }^{18}$ In this study, the effectiveness of cellulose extraction with the assistance of ultrasound at different sonication power and treatment time at low operating temperatures has been studied. The purity of the obtained cellulose was assessed and characterized by Fourier transform infrared (FTIR) spectroscopy and thermogravimetric analysis (TGA).

\section{EXPERIMENTAL \\ Chemicals}

The kapok fiber used in this study was obtained from Pahang, Malaysia. All the chemicals used in this experiment, such as chloroform $\left(\mathrm{CHCl}_{3}\right)$, methanol $\left(\mathrm{CH}_{3} \mathrm{OH}\right)$, sodium chlorite $\left(\mathrm{NaClO}_{2}, 0.7 \% \mathrm{w} / \mathrm{v} \mathrm{sol}\right)$, acetic acid $\left(\mathrm{CH}_{3} \mathrm{COOH}\right)$ and sodium hydroxide $(\mathrm{NaOH})$ pellets were purchased from R\&M Chemicals.

\section{Pretreatment for dewaxing}

In this stage, $2 \mathrm{~g}$ of kapok fibers were prepared and mixed with $200 \mathrm{~mL}$ of chloroform $\left(\mathrm{CHCl}_{3}\right)$ in a 250 $\mathrm{mL}$ round bottom flask. The mixture was refluxed for $2 \mathrm{~h}$. The $\mathrm{CHCl}_{3}$-treated fiber was then filtered, washed with methanol, and dried in an oven (WTC Binder ED 115 ) at $40{ }^{\circ} \mathrm{C}$ until a constant weight was achieved. After that, $8 \mathrm{~g}$ of $\mathrm{CHCl}_{3}$-treated fiber was added into a $1 \mathrm{~L}$ beaker with $800 \mathrm{~mL}$ of distilled water. The mixture was heated for $2 \mathrm{~h}$ at 70 to $80{ }^{\circ} \mathrm{C}$. The fiber was then filtered and dried.

\section{Solvent delignification}

In the conventional delignification process, $3 \mathrm{~g}$ of $\mathrm{CHCl}_{3}$-treated fibers were mixed with $300 \mathrm{~mL}$ of sodium chlorite $\left(\mathrm{NaClO}_{2}, 0.7 \%\right)$ and $2 \mathrm{~mL}$ of acetic acid in a $500 \mathrm{~mL}$ beaker. The mixture was heated at 70 ${ }^{\circ} \mathrm{C}$ for $3 \mathrm{~h}$ by using a digital hotplate magnetic stirrer (Dragon Lab MS-H280-Pro). The mixture was stirred constantly during heating. After the completion of heating, the fiber was filtered and washed extensively with methanol and followed by distilled water. The delignification process was repeated 3 times. After the final round of washing the $\mathrm{NaClO}_{2}$-treated fiber, it was dried in an oven at $40{ }^{\circ} \mathrm{C}$ until constant weight was achieved.

\section{Ultrasound-assisted extraction (UAE) on delignification}

In the UAE delignification process, the same chemical mixture as in the case of solvent delignification was prepared in a $500 \mathrm{~mL}$ conical flask. The conical flask was then immersed into the ultrasound water bath tank $(53 \mathrm{kHz}-350 \mathrm{~W}$, sk7210HP, KUDOS, China) with $40 \%$ sonication power. The frequency and temperature of the tank were maintained at $53 \mathrm{kHz}$ and $40{ }^{\circ} \mathrm{C}$, respectively. The mixture was treated for 20, 40 and $60 \mathrm{~min}$, respectively. After the treatment, the fiber was filtered and washed extensively with methanol and then with distilled water. The UAE delignification process was repeated three times. After the final round of washing the $\mathrm{NaClO}_{2}$ (UAE)-treated fiber, it was dried in an oven at $40{ }^{\circ} \mathrm{C}$ until constant weight was achieved. The UAE 
delignification process was repeated with sonication power at $70 \%$ and $100 \%$.

\section{Alkaline treatment}

The last stage in the extraction process consisted in the removal of hemicelluloses with $\mathrm{NaOH}$. A NaOH solution was prepared by adding $40 \mathrm{~g}$ of $\mathrm{NaOH}$ pellets into $1 \mathrm{~L}$ of distilled water in a $1 \mathrm{~L}$ volumetric flask. The flask was shaken until the pellets fully dissolved. 3 $\mathrm{g}$ of dried $\mathrm{NaClO}_{2}$-treated fibers were added to $300 \mathrm{~mL}$ of $\mathrm{NaOH}$ solution in a $500 \mathrm{~mL}$ beaker. The mixture was heated to $85{ }^{\circ} \mathrm{C}$ for $4 \mathrm{~h}$ with a digital hotplate magnetic stirrer. The mixture was constantly stirred. The $\mathrm{NaOH}$-treated fiber was then filtered and washed comprehensively with aqueous acetic and then with distilled water. The kapok cellulose fiber was dried in an oven at $40{ }^{\circ} \mathrm{C}$ until constant weight was achieved.

\section{Fourier-transform infrared (FTIR) spectroscopy}

FTIR spectroscopy was used to analyse the characteristics of the kapok cellulose. The FTIR spectra of the raw and chemical treated kapok fibers were obtained with a Nicolet ${ }^{\mathrm{TM}}$ iS ${ }^{\mathrm{TM}} 5$ FTIR spectrometer. The spectra were generated in the range from $600 \mathrm{~cm}^{-1}$ to $4000 \mathrm{~cm}^{-1}$ at a resolution of $4 \mathrm{~cm}^{-1}$, with a total of 20 scans for each sample.

\section{Thermogravimetric analysis (TGA)}

The TGA of the raw and chemically treated kapok fibers was conducted with a thermogravimetric analyser (TA Instruments Q50, United States). Approximately $6 \mathrm{mg}$ of kapok cellulose was placed in an aluminium pan and heated from $30{ }^{\circ} \mathrm{C}$ to $800{ }^{\circ} \mathrm{C}$, at $10{ }^{\circ} \mathrm{C} \mathrm{min}^{-1}$, under dynamic flow of nitrogen at $50 \mathrm{~mL}$ $\min ^{-1}$. The TGA was conducted to analyse the thermal decomposition of the kapok cellulose.

\section{RESULTS AND DISCUSSION Characterization of kapok cellulose by Fourier-transform infrared (FTIR) spectroscopy}

Figure 1 shows the FTIR spectra of kapok cellulose obtained under different conditions of ultrasound-assisted extraction (UAE) treatment in the delignification process. The spectra of the kapok celluloses were first compared in terms of ultrasound sonication power to identify the optimum UAE condition in the delignification process. In the dewaxing pretreatment, the wax surface of raw kapok fiber was removed with chloroform. The existence of the carbonyl group $(\mathrm{C}=\mathrm{O})$ stretching of ester bonds and the $\mathrm{C}-\mathrm{O}$ stretching of the acetyl group were proven by the presence of peaks around $1247 \mathrm{~cm}^{-1}$ and $1714 \mathrm{~cm}^{-}$ ${ }^{1}$, respectively. Both stretching bonds were associated with ketones, aliphatic aldehydes and the esters of kapok wax. ${ }^{19}$ The removal of wax from the fiber is normally proved by the disappearance of both peaks. In Figure 1, the peak at $1247 \mathrm{~cm}^{-1}$ is hardly observed for all the spectra. Although the peak at $1714 \mathrm{~cm}^{-1}$ is slightly noticeable, the intensity of the spectra is considered low, which proves that part of the waxy surface was removed from the fiber after the chloroform treatment.

The removal of lignin from kapok fiber is commonly achieved through solvent treatment with sodium chlorite. The creation of cavitation phenomena by ultrasound contributed to speeding up the extraction process of lignin under low operating temperatures. The breakage of the cell wall caused by the cavitation phenomena increases the mobility of particles, which allows them to easily escape from the structure. According to the literature, the characteristics of lignin are commonly found in the range from $1500 \mathrm{~cm}^{-1}$ to $1600 \mathrm{~cm}^{-1} \cdot{ }^{20}$ The band peaks around $1506 \mathrm{~cm}^{-1}$ and $1557 \mathrm{~cm}^{-1}$ represent the $\mathrm{C}=\mathrm{C}$ stretching and $\mathrm{C}=\mathrm{C}$ aromatic skeletal vibration of lignin, respectively. ${ }^{21}$ The peak at $984 \mathrm{~cm}^{-1}$ represents the $\mathrm{C}-\mathrm{H}$ out of plane deformation of lignin. ${ }^{22}$ At $40 \%$ sonication power (Fig. 1i), no peak was found between $1506 \mathrm{~cm}^{-1}$ and $1557 \mathrm{~cm}^{-1}$ for $\mathrm{UAE}_{40 \%, 60 \mathrm{~min}}$ (Fig. 1i-c). This observation shows that the removal of lignin was successful, as there is no lignin left in $\mathrm{UAE}_{40 \%, 60 \mathrm{~min}}$. The significant peak in this range was found for both $\mathrm{UAE}_{40 \%, 20 \mathrm{~min}}$ (Fig. 1i-a) and $\mathrm{UAE}_{40 \%, 40 \mathrm{~min}}$ (Fig. $1 \mathrm{i}-\mathrm{c})$. Although the peak intensity is not strong, the presence of the peak does prove that 20 and $40 \mathrm{~min}$ of treatment were not sufficient enough to completely remove the lignin from the kapok fiber.

At $70 \%$ sonication power (Fig. 1ii), the spectrum of $\mathrm{UAE}_{70 \%, 20}$ min (Fig. 1ii-a) has a similar trend as the spectrum of $\mathrm{UAE}_{40 \%, 60 \text { min }}$ in the range from $1500 \mathrm{~cm}^{-1}$ to $1600 \mathrm{~cm}^{-1}$. The peak indicates that the characteristics of lignin were not observable for $\mathrm{UAE}_{70 \%, 20 \mathrm{~min}}$. However, both spectra of $\mathrm{UAE}_{70 \%, 40 \mathrm{~min}}$ (Fig. 1ii-b) and $\mathrm{UAE}_{70 \% \text {, }}$ 60 min (Fig. 1ii-c) have a significant peak appearing in the range from $1500 \mathrm{~cm}^{-1}$ to $1600 \mathrm{~cm}^{-1}$, which shows that there is still lignin left in the structure. The removal of lignin with UAE $70 \%$ proved to be sufficient with shorter treatment time. The cavitation channels created by ultrasound sonication have remained in the structure throughout the treatment, allowing the extracted component the opportunity to enter back the structure through the same pathway. As the treatment time increased, the extracted component 


\section{JIA JUN POON et al.}

has higher chances to re-enter the cell structure. At $100 \%$ sonication power, no peak was found with $\mathrm{UAE}_{100 \%, 20 \mathrm{~min}}$ (Fig. 1iii-a) between $1500 \mathrm{~cm}^{-}$ ${ }^{1}$ and $1600 \mathrm{~cm}^{-1}$. Although $\mathrm{UAE}_{100 \%, 40 \mathrm{~min}}$ (Fig. 1iii-b) and $\mathrm{UAE}_{100 \%, 60}$ min (Fig. 1iii-c) have a significant peak appearing in this range, the peak intensity for the 40 min treatment is much lower compared to that of the 60 min treatment.
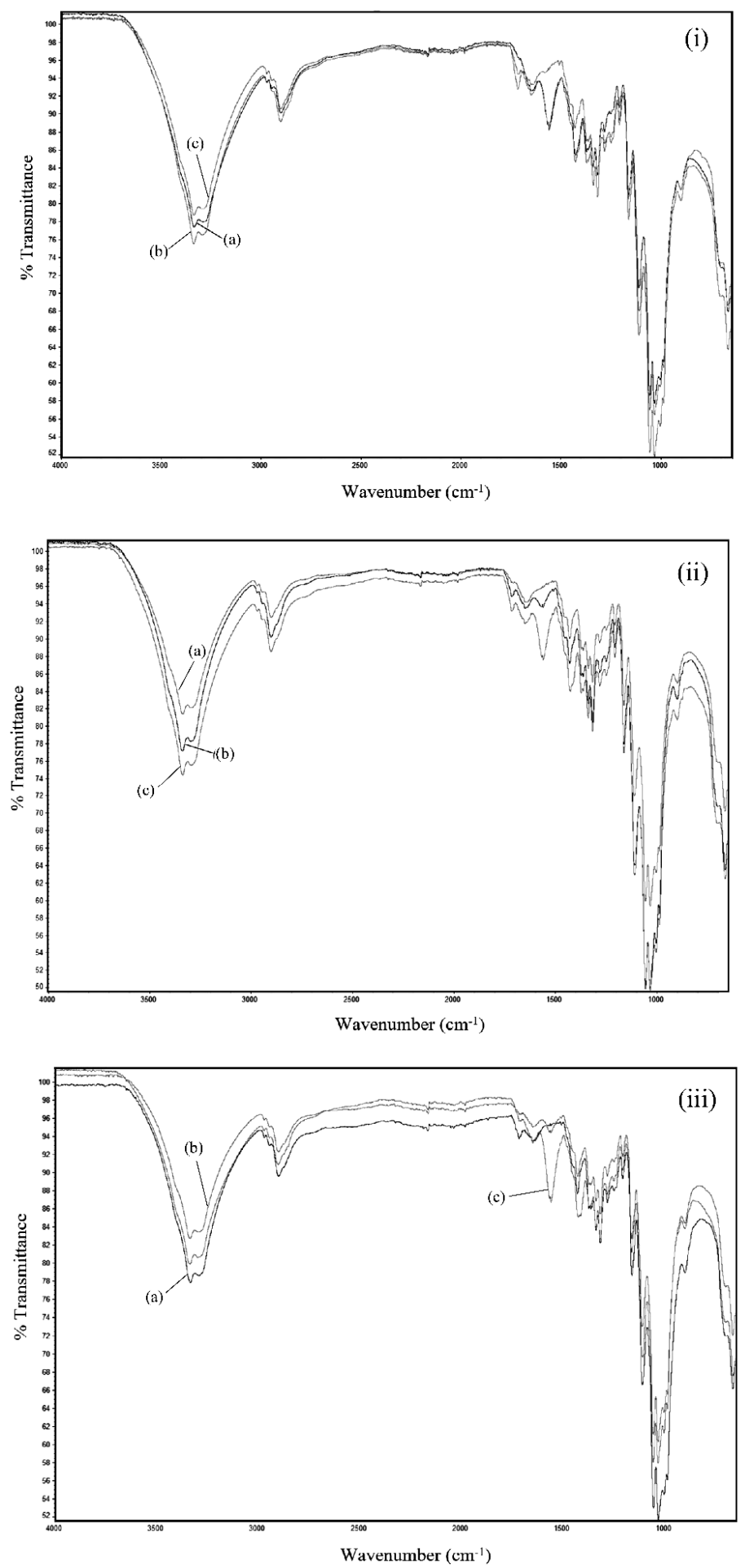

Figure 1: FTIR spectra of kapok cellulose extracted with UAE at (i) $40 \%$, (ii) $70 \%$ and (iii) $100 \%$ sonication power for (a) $20 \mathrm{~min}$, (b) $40 \mathrm{~min}$ and (c) $60 \mathrm{~min}$ 
Delignification

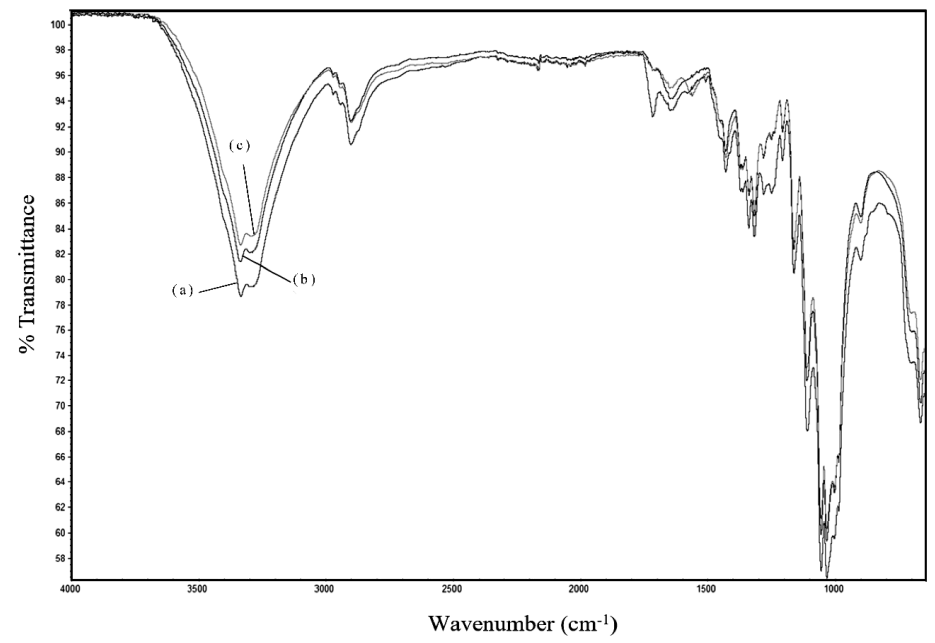

Figure 2: FTIR sprectra of kapok cellulose extracted with (a) UAE $40 \%$ for $60 \mathrm{~min}$, (b) UAE $70 \%$ for 20 min and (c) UAE $100 \%$ for $40 \mathrm{~min}$

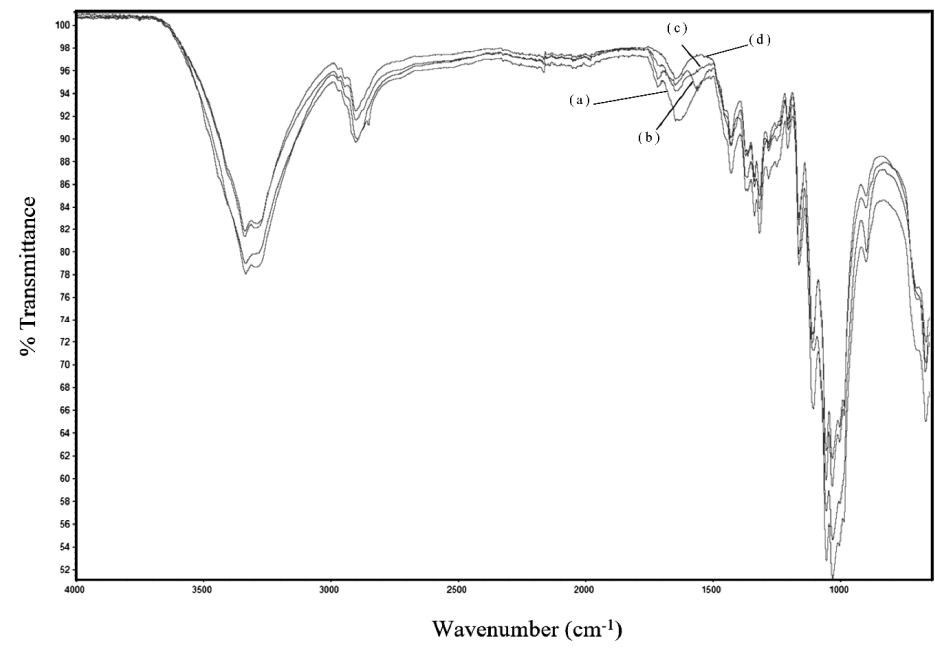

Figure 3: FTIR spectra of (a) raw kapok fiber, (b) solvent-extracted kapok cellulose, (c) kapok cellulose with UAE 70\% for $20 \mathrm{~min}$ and (d) commercial cellulose

Hemicelluloses were removed via alkaline treatment with sodium hydroxide. The peak found around $1714 \mathrm{~cm}^{-1}$ represents the $\mathrm{C}=\mathrm{O}$ stretching vibration of the ester group, which is mainly associated with hemicelluloses and partly with lignin. ${ }^{23}$ However, FTIR spectroscopy is not sufficient to validate the existence of lignin and hemicelluloses as the representation peaks in the spectra for both components are closely similar to those of cellulose. ${ }^{22}$ In comparison studies, the peak intensity in the overall spectra allows identifying which treatment has a better extraction effect.

In the spectra of the celluloses, the band at $3331 \mathrm{~cm}^{-1}$ represents the $\mathrm{O}-\mathrm{H}$ stretching vibration, which is associated with the presence of the hydroxyl $(\mathrm{OH})$ group..$^{22}$ The band at $2899 \mathrm{~cm}^{-1}$ is attributed to the $\mathrm{C}-\mathrm{H}$ symmetric and asymmetric stretching vibration of all hydrocarbon constituents in polysaccharides. ${ }^{24}$ The disappearance of both peaks shows that part of the $\mathrm{OH}$ group and $\mathrm{C}-\mathrm{H}$ stretching vibration of the hydrocarbon have been removed. The peak allocated at $1645 \mathrm{~cm}^{-1}$ is associated with the deformation of water molecules absorbed in cellulos $^{24}$ and also with the carbonyl group. The band peaks around 1361 and $1427 \mathrm{~cm}^{-1}$ are mainly associated with the $\mathrm{C}-\mathrm{H}$ deformation in cellulose, lignin and hemicelluloses. The bands at 1335 and $1204 \mathrm{~cm}^{-1}$ correspond to the hydroxyl $(\mathrm{OH})$ in-plane deformation in cellulose. ${ }^{11}$ As regards the peak at $1104 \mathrm{~cm}^{-1}$, it represents the glucose ring stretching vibration and aromatic hydrocarbon in-plane deformation in cellulose 
and lignin. The peak at $1028 \mathrm{~cm}^{-1}$ is due to $\mathrm{C}-\mathrm{O}$ stretching in the secondary hydroxide group, which is related to cellulose and lignin. ${ }^{22}$ Lastly, the peak around $897 \mathrm{~cm}^{-1}$ is attributed to the presence of $\beta$-glucoside linkage between glucose units in the cellulose and also to the deformation of glucose ring stretching. ${ }^{11}$

Based on the comparison studies on UAEtreated kapok cellulose, it may be concluded that the overall spectral intensity of $\mathrm{UAE}_{40 \%, 60 \mathrm{~min}}$ in Figure $1 \mathrm{i}$ is the lowest, whereas $\mathrm{UAE}_{70 \%, 20 \mathrm{~min}}$ and $\mathrm{UAE}_{100 \%}, 40 \mathrm{~min}$ provided better extraction outcomes, compared to the others, as shown in Figure 1ii and Figure 1iii, respectively. These three UAE-treated kapok celluloses were further compared to identify the optimum conditions of $\mathrm{UAE}$ in the delignification process. Figure 2 combined the spectra from Figure 1i-c, Figure 1ii$a$ and Figure 1iii-b to offer a clear image of the difference among the spectra and for easy analysis. Overall, the intensity of the spectra of $\mathrm{UAE}_{70 \%, 20}$ min and $\mathrm{UAE}_{100 \%, 40 \mathrm{~min}}$ is similar in the range from $600 \mathrm{~cm}^{-1}$ to $3700 \mathrm{~cm}^{-1}$. Both spectra also have much lower intensity than that of $\mathrm{UAE}_{40 \%, 60 \mathrm{~min}}$. This shows that, with higher sonication power, a better extraction outcome can be achieved for shorter treatment duration. However, there is a low-intensity lignin characteristic peak found in the spectrum of $\mathrm{UAE}_{100 \%, 40 \mathrm{~min}}$. This indicates that $\mathrm{UAE}_{70 \%, 20 \mathrm{~min}}$ is the optimum UAE treatment for the extraction of cellulose from kapok fiber, as revealed by FTIR analysis.

The FTIR spectrum of the optimum UAE $(70 \%, 20 \mathrm{~min})$ treated kapok cellulose was compared with those of raw kapok fiber, solventextracted kapok cellulose and commercial cellulose, to identify which treatment has the best extraction outcome. In Figure 3, the spectra of UAE (Fig. 3c) and solvent-extracted kapok cellulose (Fig. 3b) have a much lower intensity, compared to the spectrum of the raw kapok fiber (Fig. 3a). This proved that both UAE and solvent treatment have a significant effect on the extraction of cellulose from kapok fiber. The differences in intensity show that there is a reduction in components after both treatments. Comparing the conventional (solvent-extraction) and UAE method, the overall spectral intensity for both treatments are similar to each other. However, it seems that the solvent-extracted kapok cellulose has a lignin characteristic peak of light intensity appearing in the spectrum, while this peak disappeared in the case of UAE. Moreover, the characteristic peak of hemicelluloses was found in both UAE and solvent-extracted spectra, with solvent-extracted kapok cellulose having slightly lower peak intensity, compared to that obtained by the UAE method. The spectra of solvent-extracted and UAE kapok celluloses are similar to the spectra of commercial cellulose, which proved that cellulose was successfully obtained through both treatments. Based on FTIR analysis, both solvent-extraction and UAE methods are sufficient to obtain pure cellulose from kapok fiber. However, in terms of treatment duration and operating temperature, the UAE method will be preferred, as it allows obtaining cellulose with similar purity under lower operating temperatures and shorter treatment time.

\section{Thermogravimetric analysis (TGA)}

Thermal analysis of kapok cellulose was conducted to determine the purity of cellulose achieved from the extraction process by analysing the quantity of lignin and hemicelluloses remained in the structure of kapok fiber. Figure 4 shows the TGA thermograms of kapok cellulose obtained under different conditions of ultrasoundassisted extraction (UAE) treatment in the delignification process. In the analysis of cellulose purity with TGA, the "shoulder" and "tail" are usually observed to determine the presence of hemicelluloses and lignin. The "shoulder" around 250 to $300{ }^{\circ} \mathrm{C}$ is attributed to the thermal degradation of hemicelluloses in an inert atmosphere, ${ }^{11}$ while the "tail" of the thermograms appearing in the high-temperature range (400 to $600{ }^{\circ} \mathrm{C}$ ) is ascribed to the degradation of lignin. ${ }^{25}$

Figure 4i shows that the thermograms of UAE 40\%, 20 min (Fig. 4i-a), UAE $40 \%, 40$ min (Fig. 1i-b) and $\mathrm{UAE}_{40 \%, 60 \mathrm{~min}}$ (Fig. 1i-c) are closely similar to each other. In this case, the observation on the "shoulder" and "tail" of the thermogram is not sufficient enough to justify which treatment yields a higher purity cellulose. However, it does show that the "shoulder" and "tail" of all three thermograms were not observable, which proved that not much of hemicelluloses and lignin remained in the UAE treated sample. The thermal degradation of cellulose usually occurs between 300 to $350{ }^{\circ} \mathrm{C}$. In this specific range, a larger weight difference indicates higher content of cellulose present in the treated sample. In comparison, $\mathrm{UAE}_{40 \%, 20 \mathrm{~min}}$ has a larger weight reduction from 300 to $350{ }^{\circ} \mathrm{C}$, which shows that the purity of cellulose achieved by this treatment 
is slightly higher compared to that of $\mathrm{UAE}_{40 \%, 40}$ min and $\mathrm{UAE}_{40 \%, 60 \mathrm{~min}}$. In this case, the analysis by TGA yields a different outcome from that of FTIR, as it indicates that a shorter treatment time with $20 \%$ sonication has a better extraction effect.

The thermograms in Figure 4ii and Figure 4iii are similar to that in Figure 4i. Figure 4ii shows the thermograms of kapok cellulose treated with $\mathrm{UAE}$ at $70 \%$ sonication for $20 \mathrm{~min}, 40 \mathrm{~min}$ and 60 min treatment time. In Figure 4ii, the "shoulder" peak of $\mathrm{UAE}_{70 \%, 40 \mathrm{~min}}$ (Fig. 4ii-b) is more obvious compared to those of $\mathrm{UAE}_{70 \%, 20 \mathrm{~min}}$
(Fig. 4ii-a) and $\mathrm{UAE}_{70 \%, 60 \text { min }}$ (Fig. 4ii-c), which indicates the removal of hemicelluloses is less efficient with $\mathrm{UAE}_{70 \%, 40 \mathrm{~min}}$. The "tail" was not found in all three thermograms, which indicates the removal of lignin. In this comparison, the cellulose obtained from $\mathrm{UAE}_{70 \%, 20}$ min has the highest purity, as lower weight was achieved after the degradation of cellulose at $350{ }^{\circ} \mathrm{C}$. In Figure 4iii, the purity of $\mathrm{UAE}_{100 \%, 40 \mathrm{~min}}$ (Fig. 4iii-b) is the highest. The observable "shoulder" of UAE $100 \%, 20$ $\min$ (Fig. 4iii-a) in the range from 250 to $300{ }^{\circ} \mathrm{C}$ indicates the presence of lignin.
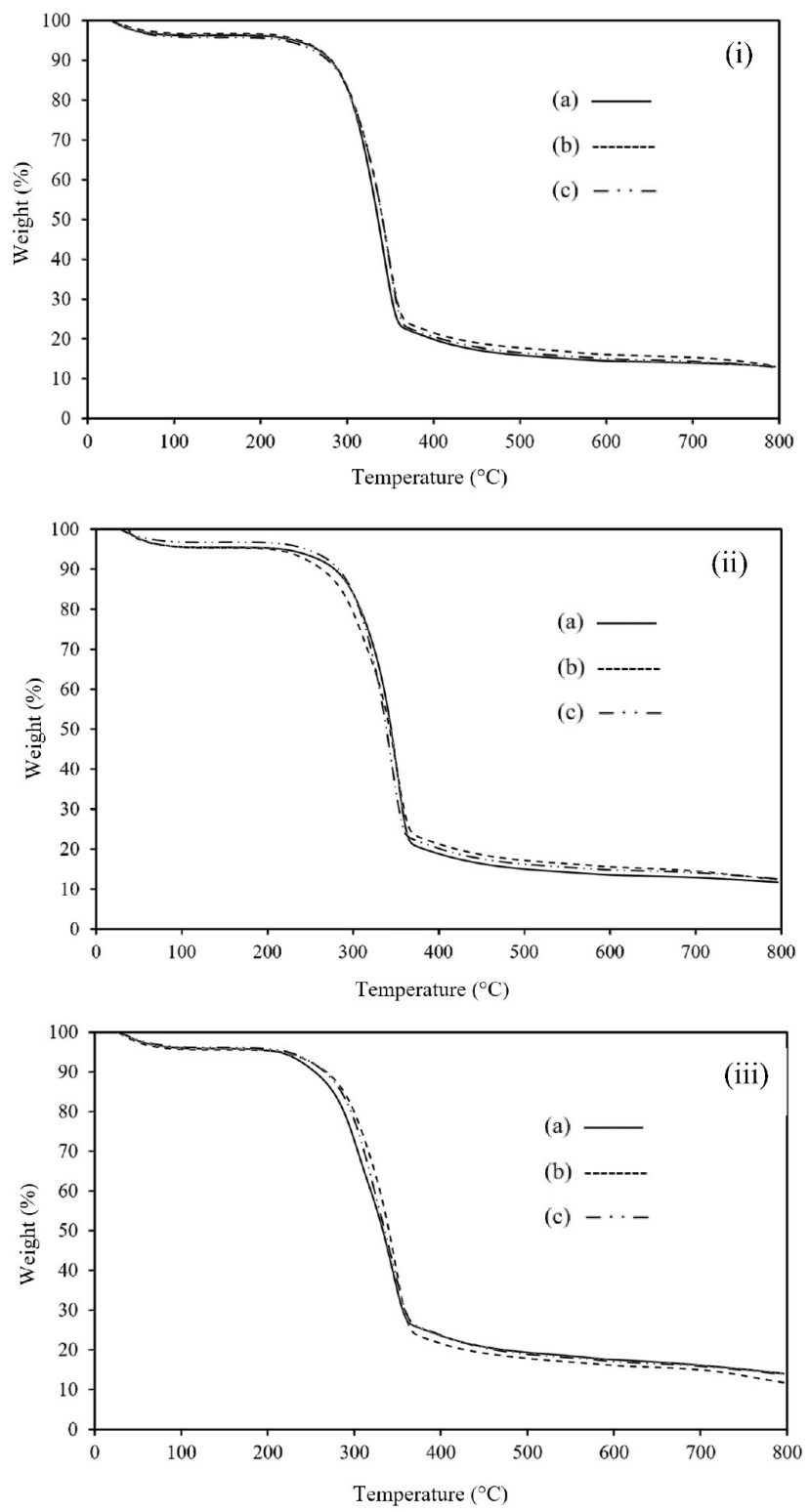

Figure 4: TGA curves of kapok cellulose extracted with UAE at (i) 40\%, (ii) $70 \%$ and (iii) $100 \%$ sonication power for (a) $20 \mathrm{~min}$, (b) $40 \mathrm{~min}$ and (c) $60 \mathrm{~min}$ 


\section{JIA JUN POON et al.}

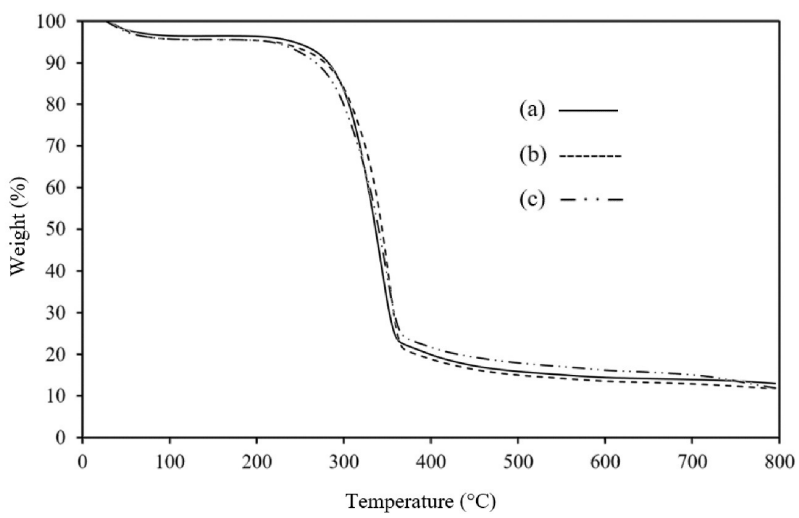

Figure 5: TGA curves of kapok cellulose extracted with (a) UAE $40 \%$ for 20 min, (b) UAE $70 \%$ for 20 min and (c)

UAE $100 \%$ for $40 \mathrm{~min}$
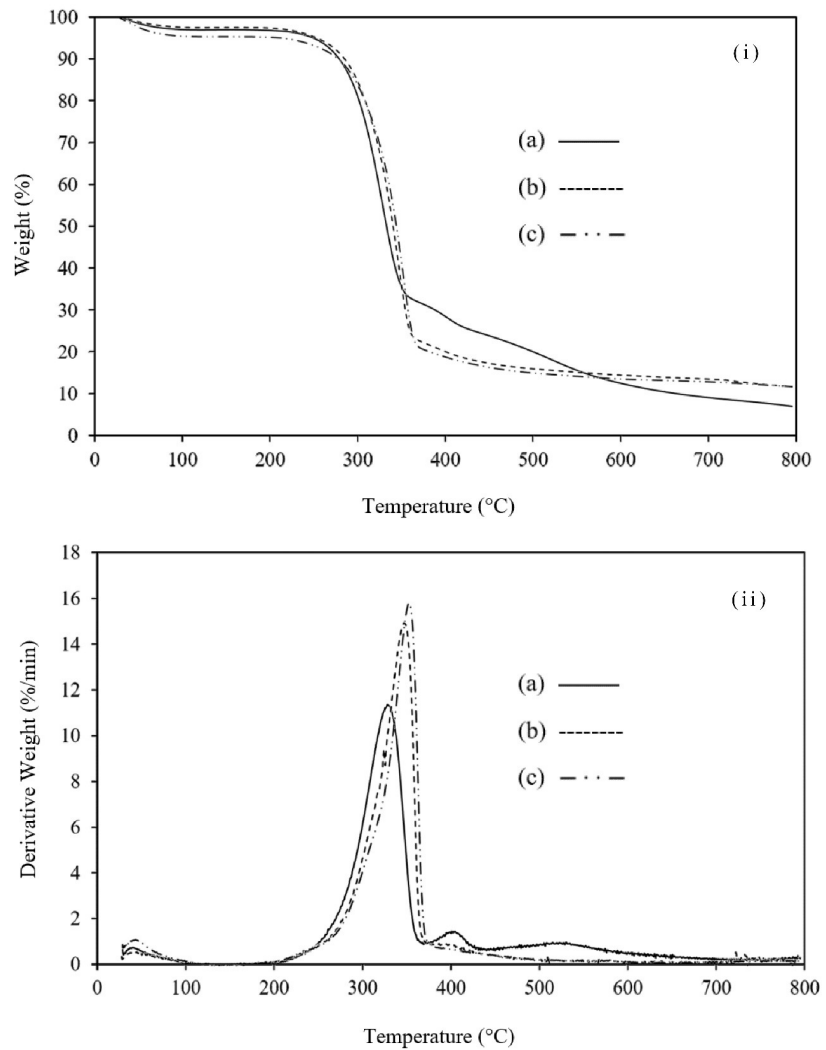

Figure 6: (i) TGA and (ii) DTG curves of raw kapok fiber, (b) solvent-extracted cellulose and (c) UAE $\mathrm{E}_{70 \%, 20 \mathrm{~min}}$ extracted cellulose

The thermograms of all UAE treated kapok celluloses presented a similar flow, which shows the extraction capacity is very similar under the observed conditions. However, some treatment combinations (sonication power and time) demonstrate a slight improvement in the removal of other lignocellulosic components, besides cellulose. Based on the comparison studies of UAE treated kapok cellulose, it may be concluded that the purity of cellulose achieved with $\mathrm{UAE}_{40 \%}$,
$20 \mathrm{~min}$ is the highest (Fig. 4i), whereas, in Figure 4ii and Figure 4iii, the celluloses with the highest purity are $\mathrm{UAE}_{70 \%, 20}$ min and $\mathrm{UAE}_{100 \%, 40 \mathrm{~min}}$, respectively. These three samples were further compared to identify the optimum UAE conditions to achieve high purity cellulose. Figure 5 combined the spectra from Figure 4i-a, Figure 4ii-a and Figure 4iii-b to obtain a clear image of the difference between the curves and for easy analysis. With close similarity in the thermograms 
of the three samples, $\mathrm{UAE}_{70 \%, 20 \mathrm{~min}}$ demonstrated a slightly better flow in the thermograms, as the "shoulder" and "tail" are not that obvious when compared to the other two samples. The weight reduction in the range of cellulose degradation is also the highest, compared to $\mathrm{UAE}_{40 \%, 20 \mathrm{~min}}$ and $\mathrm{UAE}_{100 \%, 40}$ min. Overall, the TGA analysis indicates that $\mathrm{UAE}_{70 \%, 20} \mathrm{~min}$ is the optimum ultrasound treatment to achieve high purity cellulose.

The optimum UAE treatment was compared with solvent-extracted cellulose (conventional method) to identify which method can achieve higher purity cellulose. Figure 6i presents the TGA thermograms and corresponding derivative thermogravimetry (DTG) curves of raw kapok fiber and the treated kapok cellulose. The "shoulder" of the raw kapok fiber (Fig. 6i-a) is slightly seen, compared to the "shoulder" of the solvent-extracted cellulose (Fig. 6i-b) and UAE kapok cellulose (Fig. 6i-c). However, the peaks obtained from the three samples are actually similar to each other. The differences between the peaks are very small. This might due to the fact that the hemicelluloses structure is actually very similar to that of cellulose, as they share some functional groups and components. Some of the cellulose was removed along with the hemicelluloses.

In terms of cellulose, the end-point (peak) around $350{ }^{\circ} \mathrm{C}$ is located at a higher weight loss "position", compared to the case of the treated kapok fiber. This observation indicates that the purity of cellulose in the treated kapok fiber is much higher, compared to that of the raw fiber. In comparison, the "tail" of the raw kapok fiber is easily observable, which proved the presence of lignin. The "tail" with a flat distribution demonstrated in both treated fibers (solventextracted and UAE) indicated that the lignin has been successfully removed. The DTG curve in Figure 6ii was constructed to support the observation on the TGA thermogram. In DTG, the derivative weight in the range from 300 to $350{ }^{\circ} \mathrm{C}$ shows that UAE and solvent-extracted celluloses have much higher peaks, compared to raw kapok fiber, which shows that higher cellulose content inside the fiber. The disappearance of the peak for the UAE and solvent-extracted kapok celluloses in the range from 400 to $600{ }^{\circ} \mathrm{C}$ indicates the removal of lignin.

The thermogram of UAE treated fiber is very similar to that of the solvent-extracted fiber. However, the time consumption in removing lignin with ultrasound is much lower, compared with the conventional method (solvent-extracted) and the required operating temperature of the treatment is also much lower. The removal of lignin by the conventional method (solventextracted) required $9 \mathrm{~h}$ to complete the treatment, whereas UAE required only $1 \mathrm{~h}$. The operating temperature was reduced from $70{ }^{\circ} \mathrm{C}$ to $40{ }^{\circ} \mathrm{C}$ in the UAE treatment. The assistance of the ultrasound sonication treatment in the delignification of kapok fiber could produce high purity cellulose at lower operating temperatures with shorter treatment time. In TGA, the thermogram was generated with the analytical data (weight of sample and temperature) obtained from the analysis. The findings from TGA were normally presented in the thermogram. In this study, since the thermograms of solvent-treated and $\mathrm{UAE}_{70 \%, 20}$ min treated kapok fibers were similar to each other, the analytical data generated from the analysis were used to achieve more accurate results. According to the analytical data, the content of lignin was reduced from $15.92 \%$ (raw kapok fiber) to $5.64 \%$ and $5.29 \%$ with solvent extraction and $\mathrm{UAE}_{70 \%, 20}$ min treatment, respectively. Moreover, the ultrasound not only assists the delignification, but, somehow, it also has a significant effect on the removal of hemicelluloses. The hemicelluloses were reduced from $14.09 \%$ (raw kapok fiber) to $10.52 \%$ and $9.42 \%$ for solvent extraction and $\mathrm{UAE}_{70 \%, 20 \mathrm{~min}}$ treatment, respectively. This shows an improvement not only in the delignification, but in the removal of hemicelluloses. The cavitation phenomena (breakage of the cell wall) created during sonication also provided a certain benefit during the alkaline treatment.

\section{CONCLUSION}

In conclusion, the effectiveness of extracting lignin from kapok fiber with the assistance of ultrasound-solvent extraction was demonstrated by both FTIR analysis and TGA. The results showed ultrasound-assisted extraction in the removal of lignin from kapok fiber is much more efficient at lower temperatures and shorter treatment time, compared to the conventional method. The content of lignin found in raw kapok fiber was $15.92 \%$. It was reduced to $5.64 \%$ after solvent extraction and to $5.29 \%$ after $\mathrm{UAE}_{70 \%, 20}$ $\min$ treatment. The hemicelluloses were also reduced from $14.09 \%$ to $10.52 \%$ and $9.42 \%$ after solvent extraction and $\mathrm{UAE}_{70 \%, 20 \mathrm{~min}}$, respectively. Although the purity obtained from solvent 
extraction and UAE (lignin part) is similar, it can be easily achieved with UAE under much lower operating temperature and treatment duration. The analyses performed showed that kapok fiber treated with $70 \%$ sonication power at $40{ }^{\circ} \mathrm{C}$ for 20 $\min$ is the most effective combination of treatment to obtain high purity cellulose, after three runs of the UAE delignification process. With the assistance of ultrasound, the treatment time was reduced from $9 \mathrm{~h}$ to $1 \mathrm{~h}$ in total and the operating temperature was reduced from $70{ }^{\circ} \mathrm{C}$ to $40{ }^{\circ} \mathrm{C}$. The ultrasound treatment in the delignification process has also significantly improved the removal of hemicelluloses to obtain high purity cellulose.

ACKNOWLEDGEMENT: This research did not receive any specific grant from funding agencies from the public, commercial or not-for-profit sectors.

\section{REFERENCES}

1 D. Klemm, B. Heublein, H. P. Fink and A. Bohn, Angew. Chem. Int. Ed., 44, 3358 (2005), http://doi.org/10.1002/anie.200460587

2 A. Demirbas, Energ. Sources, Part A, 29, 419 (2007), http://doi.org/10.1080/009083190965820

3 M. A. Mohamed, W. N. W. Salleh, J. Jaafar, A. F. Ismail, M. Abd Mutalib et al., Carbohyd. Polym., 157, 1892

https://doi.org/10.1016/j.carbpol.2016.11.078

(2017),

4 J. Shokri and K. Adibki, in "Cellulose-Medical, Pharmaceutical and Electronic Applications", edited by Theo van de Ven and Louis Godbout, IntechOpen, 2013, p. 47, http://doi.org/10.5772/55178

5 T. Nilsson and C. Björdal, Int. Biodeterior. Biodegrad., $\quad 61, \quad 11 \quad$ (2008), http://doi.org/10.1016/j.ibiod.2007.06.009

6 P. Song, J. Cui, J. Di, D. Liu, M. Xu et al., ACS Nano, 14, $595 \quad$ (2020), http://doi.org/10.1021/acsnano.9b07063

7 R. B. Gapusan and M. D. L. Balela, Mater. Chem. Phys., 243, 122682 (2020), http://doi.org/10.1016/j.matchemphys.2020.122682

8 Y. Zheng, J. Wang, Y. Zhu and A. Wang, J. Environ. Sci., 27, $21 \quad$ (2015), https://doi.org/10.1016/j.jes.2014.09.026

9 A. U. Rahmah and M. A. Abdullah, Desalination, 266, 51

(2011), http://doi.org/10.1016/j.desal.2010.08.001

10 Y. Qi, F. Xu. L. Cheng, R. Zhang, L. Liu et al., Trend. Text. Eng. Fash. Technol., 2, 205 (2018), http://doi.org/10.31031/tteft.2018.02.000543

11 S. F. S. Draman, R. Daik, F. A. Latif and S. M. ElSheikh, BioResources, 9, 8 (2014), http://doi.org/10.15376/biores.9.1.8-23

12 A. N. Frone, D. M. Panaitescu and D. Donescu, UPB Sci. Bull. Ser. B Chem. Mater. Sci., 73, 133 (2011) 13 F. Cheng, X. Zhao and Y. Hu, Bioresour. Technol., 249, 969

(2018),

https://doi.org/10.1016/j.biortech.2017.10.089

14 L. Neubert, J. Sunthornvarabhas, M. Sakulsombat and K. Sriroth, Cellulose Chem. Technol., 54, 301 (2020),

https://doi.org/10.35812/CelluloseChemTechnol.2020. 54.32

15 M. A. Abdullah, M. S. Nazir, M. R. Raza, B. A. Wahjoedi and A. W. Yussof, J. Clean. Prod., 126, 686 (2016), https://doi.org/10.1016/j.jclepro.2016.03.107

16 F. Chemat, N. Rombaut, A. G. Sicaire, A. Meullemiestre, A. S. Fabiao-Txier et al., Ultrason. Sonochem., $\quad 34, \quad 540 \quad$ (2017), http://doi.org/10.1016/j.ultsonch.2016.06.035

17 A. Ebringerová and Z. Hromádková, Cent. Eur. J. Chem., 8, 243 (2010), http://doi.org/10.2478/s11532010-0006-2

18 S. C. Mandal, V. Mandal and A. K. Das, "Essentials of Botanical Extraction: Principles and Applications", Elsevier Academic Press Inc., 2015, p. 63, http://doi.org/10.1016/C2014-0-02889-4

19 M. A. Abdullah, A. U. Rahmah and Z. Man, J. Hazard. Mater., 177, $683 \quad$ (2010), http://doi.org/10.1016/j.jhazmat.2009.12.085

20 J. I. Morán, V. A. Alvarez, V. P. Cyras and A.

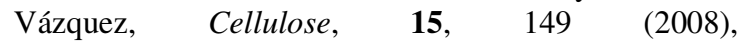
http://doi.org/10.1007/s10570-007-9145-9

21 A. Bono, P. H. Ying, F. Y. Yan, C. L. Muei, R. Sarbatly et al., Adv. Nat. Appl. Sci., 3, 5 (2009)

22 M. F. Rosa, E. S. Medeiros, J. A. Malmonge, K. S. Gregorski, D. F. Wood et al., Carbohyd. Polym., 81, 83 (2010), http://doi.org/10.1016/j.carbpol.2010.01.059

23 P. Peng and D. She, Carbohyd. Polym., 112, 701 (2014), http://doi.org/10.1016/j.carbpol.2014.06.068

24 M. Poletto, V. Pistor, M. Zeni amd A. J. Zattera, Polym. Degrad. Stab., 96, 679 (2011), http://doi.org/10.1016/j.polymdegradstab.2010.12.007

25 F. Yao, Q. Wu, Y. Lei, W. Guo and Y. Xu, Polym. Degrad. Stab., 93, $90 \quad$ (2008), http://doi.org/10.1016/j.polymdegradstab.2007.10.012 